Cigarette fires

\section{Heroes needed to conquer burning issues}

\section{B Pless}

\section{Editor Barry Pless introduces articles on cigarette safety by two of the field's most dedicated campaigners}

lthough I have inveighed against
what often appears to be an
inappropriate use of the word
"hero" in the context of injury preven-
tion, ', some legitimate uses remain.
Anyone who devotes more than
30 years to a single cause is surely
entitled to be called heroic, perhaps
even iconic. Injury prevention is a field
that needs more such leaders. To be
sure, names like Haddon, Baker, and
Rivara come to mind; each is justly
renown and if not of iconic stature
already, destined to become such. They
are excellent examples that more of us
need to follow if the field is to flourish.
Some, however, such as Andrew
McGuire, who runs the Trauma
Foundation in San Fransisco, remain
unsung and perhaps unknown. His
lengthy battle to prevent burns by
requiring tobacco companies to produce
a fire safe cigarette, are inspiring. His
recent success prompted me to ask him

to write the special feature in this issue describing how it came about [see page 264]. I did so because I wanted to illustrate how advocacy really works and to pay tribute to his commitment in this prolonged struggle.

Another such hero is Rick Stanwick, Chief Medical health officer for the Vancouver Island Health Authority. He is a former member of the editorial board of this journal and because he too is a renowned advocate, I asked him to write a commentary about the McGuire saga [see page 259]. Stanwick's history of successes as an advocate includes his role in having Canada's fire retardant sleepwear law passed, the banning of lawn darts, and, most recently, an imaginative campaign to promote the use of seatbelts and bike helmets using decals on the sides of city buses. Perhaps his greatest triumph, however, was to make Victoria entirely smoke free. This measure, which will reduce many smoke related diseases, is also certain to reduce fire deaths, the goal of McGuire's efforts. An excellent account of his crusade is provided in a book entitled Smoke-Free: How one city successfully banned smoking in all indoor public places. The book notes that "As our region moved through the process of the bylaw and its implementation, the smoking rate in the general public fell from $22 \%$... to less than $15 \% .^{\prime 2}$

As regular readers will know, I am a firm believer in regulatory and legislative solutions to improving injury prevention. However, regulation without some degree of enforcement is likely to fall well short of the mark. With it, the results can be spectacular.

The example of these crusaders is inspiring. Their message-that for successful advocacy persistence is essential-is one that we must try to emulate. We need more heroes like McGuire and Stanwick; advocates prepared to risk their careers and financial security for causes in which they believe deeply.

Injury Prevention 2005;1 1:258.

doi: 10.1136/ip.2005.010124

Correspondence to: Professor I B Pless, Editor; barry.pless@mcgill.ca

\section{REFERENCES}

1 Pless $B$. Taking risks with injury prevention. CMAJ 2002;167:767-8.

2 Mclintock B. Smoke-Free: How one city successfully banned smoking in all indoor public places. Vancouver, BC: Granville Publishing, 2004 